\title{
Gottlieb, the FDA and Dumbing Down Medicine
}

In the last few weeks several events have occurred that might impact drug approval in the US. President Donald Trump's pick for FDA commissioner, Dr. Scott Gottlieb. Gottlieb, like many of Trump's picks for administration healthcare positions, is a physician. He also has experience as deputy FDA commissioner from 2005-7. However, his confirmation hearing before the Senate Committee on Health, Education, Labor and Pensions alarmed some who say his deep ties to the pharmaceutical industry will cause a conflict of interest (1). Others praised Gottlieb as the right man to lead the FDA.

As opposed to Trump, Gottlieb denied any connection between vaccines and autism $(1,2)$. Dr. Gottlieb called the issue "one of the most exhaustively studied questions in medical history," before saying, "There is no plausible link between vaccines and autism. At some point, we have to accept 'no' for an answer." However, Gottlieb did not give a straight answer when asked to share his thoughts on drug importation. While President Donald Trump has supported increased drug importation and is reported to be working with Democratic lawmakers on drug importation legislation, Dr. Gottlieb had previously opposed the measure (1). When asked if he opposes importing cheaper drugs from foreign countries, he said, "I can tell you I have a lot of ideas that I want to work on right away on how I think we can get more product competition onto the market."

Gottlieb stated that the FDA could speed up approval of new drugs and devices (1). However, a letter to the editor published in the New England Journal of Medicine examined compared review times for new therapeutic agents that were approved by the FDA or the European Medicines Agency (EMA), the primary drug regulator in Europe, between 2011 and 2015 (3). The median total review time was 306 days (interquartile range, 239 to 371 ) at the FDA, as compared with 383 days (interquartile range, 327 to 446 ) at the EMA.

In welcome news to many physicians, Gottlieb voiced uneasiness over increasing regulation of physicians' practices (1). "My concern that the agency was losing confidence in physicians and felt it need[ed] ...to supplant their judgment for the judgment of doctors," Gottlieb said. He had previously referred to the FDA's action on Arcoxia, a pain killer that was rejected in April 2007 because of concern that it could increase the risk of heart attack and stroke with prolonged use despite being meant for short-term pain relief. Gottlieb stated the opioid epidemic would be his "highest and most immediate priority." He added that the epidemic is a "public health emergency on the order of Ebola and Zika" that requires dramatic action from the FDA. "[T]o address it now, the types of actions that we are going to need to take are going to be more dramatic, perhaps, than the types of actions we would have taken 10 years ago." 
Gottlieb did not note that some have linked the present opioid crisis to meddling by bureaucrats, administrations and politicians as an unattended consequence of the pain scale, opioid prescribing guidelines and patient satisfaction ratings (4).

Furthermore, he did not note that increasing prescribing authority has been given to non-physicians with less education and clinical experience, e.g., unsupervised nurse practitioners in the Department of Veterans Affairs (5). Whether these nonphysician clinicians will use drugs any more or less appropriately than physicians is unclear.

Richard A. Robbins, MD

Editor, SWJPCC

\section{References}

1. Dickson V. Gottlieb favors regulations that empower doctors while keeping FDA standards. Modern Healthcare. April 5, 2017. Available at: http://www.modernhealthcare.com/article/20170405/NEWS/170409965 (requires subscription, accessed 4/11/17).

2. Dodgson L. Trump has suggested vaccines cause autism - an idea that couldn't be more wrong. Business Insider. January 24, 2017. Available at: http://www.businessinsider.com/trump-vaccines-autism-wrong-2017-1 (accessed 4/11/17).

3. Downing NS, Zhang AD, Ross JS. Regulatory review of new therapeutic agents - FDA versus EMA, 2011-2015. N Engl J Med. 2017Apr 6;376:13867. [CrossRef] [PubMed]

4. Robbins RA. Pain scales and the opioid crisis. Southwest J Pulm Crit Care. 2017;14(3):119-22. [CrossRef]

5. Department of Veterans Affairs. VA grants full practice authority to advance practice registered nurses. December 14, 2016. Available at: https://www.va.gov/opa/pressrel/pressrelease.cfm?id=2847 (accessed 4/11/17). 